\title{
Urethral Sphincter Dyssynergia in Spinal Cord Injury Patients
}

\section{J. J. Wyndaele, M.D.}

Centre for Urodynamics and Re-education, Department of Urology, State University, Ghent, Belgium

\section{Summary}

On the basis of several hundreds of urodynamic investigations done in 105 SCI patients the phenomenon of urethral sphincter dyssynergia was studied.

In Upper Motor Neuron Lesion (UMNL) patients, dyssynergic contractions of the external urethral sphincter during spontaneous bladder contractions were demonstrated in $86^{\circ} \circ$ and, during bladder contractions initiated by suprapubic tapping, also in $86^{\circ}{ }_{0}$. CREDÉ manoeuvre or abdominal straining gave an augmentation of the urethral sphincter activity in $53^{\circ}{ }_{0}$. Interrupted tapping could lower a dyssynergic sphincter activity in a great number of UMNL patients. This technique of bladder stimulation was important to acquire a balanced bladder function in $28^{\circ}$ of the patients.

In patients with a non-contracting detrusor, a non-relaxing sphincter or augmentation of the sphincter spasticity with the crédé manoeuvre or abdominal straining was found in at least $50^{\circ}{ }_{0}$. The values of different forms of conservative treatment and of sphincterotomy are discussed. The final outcome of the bladder reeducation is given.

Key words: Spinal cord injury; Neuropathic bladder; Sphincter dyssynergia.

\section{Introduction}

Inappropriate contraction or failure of complete and sustained relaxation of the urethral sphincter during detrusor contraction is known as detrusor urethral sphincter dyssynergia (Yalla et al., 1982).

Such dyssynergia is one of the most common causes of unbalanced bladder function (Rossier and Fam, 1979). Dyssynergia occurs frequently in suprasacral spinal cord lesions (McGuire, 1984), but also in other neurological diseases (Blaivas and Barbalias, 1984). We reviewed this phenomenon in a group of spinal cord injury (SCI) patients. 


\section{Material and Methods}

The files of 105 SCI patients were reviewed. They were 75 males, mean age 36 years (from 10 to 76 years old) and 30 females, mean age 40 years (from 18 to 73 years old). The spinal cord injury was caused by trauma in 81 patients and by a medical cause in 24 patients. An UMN type of lesion was found in 87 patients (57 complete and 30 incomplete). Some LMN type of lesion was found in 18 patients (12 complete, 6 incomplete).

The urodynamic situation of these patients was evaluated over the years in several hundreds of urodynamic investigations. A DISA 6 channel equipment and Gaeltec microtransducers were used.

The effects of continuous and interrupted suprapubic tapping, of crédé manoeuvre and abdominal straining, had been determined during the urodynamic testing. The longterm results of these techniques were evaluated from the patients' personal medical file.

By interrupted tapping we mean the abrupt ceasing of suprapubic tapping as soon as a bladder contraction occurs or urine outflow starts. Tapping is restarted only after all urine evacuation has stopped spontaneously.

Intra- or para-sphincteric injections of anaesthetics were performed during radiocystometry. One to two $\mathrm{ml}$ of Xylocain $2^{\circ}{ }_{0}$ with Adrenaline (Nobelpharma) were injected at each side through an intramuscular needle under radioscopic control.

Vesico-ureteral reflux was looked for during radiocystometry or cystography. Sphincterotomy was performed at twelve o'clock (Madersbacher, 1976).

\section{Results}

Detrusor sphincter dyssynergia occurred during spontaneous bladder contraction in 75 patients $(86 \%)$ with UMNL. Bladder contractions provoked by suprapubic tapping showed sphincter dyssynergia in $70(86 \%)$ of the patients in whom it was examined. During the créde manoeuvre or abdominal straining, sphincter spasticity occurred in 31 of the patients $(53 \%)$ with complete data (Table I).

The effect of interrupted tapping is given in Table II. In 59 out of 65 patients with all data available $(91 \%)$ abrupt ceasing of the tapping gave a brief relaxation of the external urethral sphincter. In $44(68 \%)$ of these patients this lead to some urine outflow. By training patients in performing the interrupted tapping this technique proved important to achieve a balanced bladder function in 18 UMNL patients $(28 \%$ of the total number). In 26 other patients the method proved unusable or failed. The causes for this are given in Table III. In six patients interrupted tapping did not lead to a balanced function although an exact reason for this failure could not be found.

Of 18 patients with a non-contractile detrusor five had a non-relaxing sphincter, while this sphincter activity increased with crédé or abdominal straining in two of these patients and in a severe way in another patient. This patient was put on intermittent self-catheterisation.

Suprapubic tapping and especially interrupted tapping did not influence the sphincter activity nor did it prove to be important in bladder re-education in these patients. 
Table I Sphincter dyssynergia in UMNL patients

\begin{tabular}{|c|c|c|c|}
\hline & \multicolumn{3}{|c|}{ Number of patients } \\
\hline & $\begin{array}{l}\text { Complete lesion } \\
\text { (Total }-57 \text { patients) }\end{array}$ & $\begin{array}{l}\text { Incomplete lesion } \\
\text { (Total - } 30 \text { patients) }\end{array}$ & $\begin{array}{l}\text { Total } \\
87 \text { patients }\end{array}$ \\
\hline Detrusor sphincter dyssynergia with & & & \\
\hline Spontaneous bladder contraction & $48(0 ?)$ & 27 (0 ?) & 75 (0 ?) \\
\hline $\begin{array}{l}\text { Bladder contraction by suprapubic tapping } \\
\text { Sphincter spasticity with }\end{array}$ & 49 (0?) & $21(6 ?)$ & $70(6 ?)$ \\
\hline Crédé manoeuvre & 19 (15?) & $12(14 ?)$ & 31 (29?) \\
\hline
\end{tabular}

Table II The effect of interrupted tapping in UMNL patients

\begin{tabular}{lccc}
\hline & & \multicolumn{2}{c}{ During interrupted tapping } \\
\cline { 3 - 4 } Type lesion & Number of patients & Sphincter spasticity & Micturition \\
\hline Complete & $57(10 ?)$ & 42 & 32 \\
Incomplete & $30(12 ?)$ & 17 & 12 \\
Total & $87(22 ?)$ & 59 & 44 \\
\hline
\end{tabular}

(? = data incomplete concerning this)

Note: Please see Note in relation to Table 1.

Table III Causes for failure or non-use of interrupted tapping in 26 patients

\begin{tabular}{lc}
\hline & $\begin{array}{c}\text { Number } \\
\text { of } \\
\text { patients }\end{array}$ \\
\hline Incontinence in female patients & 4 \\
Hypocontractile detrusor & 11 \\
Hyperreflexia of detrusor & 2 \\
Indwelling catheter (bad general condition) & 2 \\
Uncooperative patient & 1 \\
Insufficient results & 6 \\
\hline
\end{tabular}

Vesico-ureteral reflux developed during a mean follow-up of 4, 7 years (one to 18 years) in 17 patients, 11 with dyssynergic sphincter and 6 with synergic sphincter. Longterm use of interrupted tapping proved not to be a hazard for the occurrence of reflux. Vesico-ureteral reflux was demonstrated in four of the 18 patients who used this technique. But the reflux disappeared spontaneously in three of them when the urinary tract became infection free. In one patient a low grade of reflux persisted for some years without alteration of the upper urinary tract.

\section{Specific treatment for the sphincter dyssynergia}

Baclofen. To estimate the value of its use in our patients proved difficult as many patients were treated with this drug for general spasticity. In six patients the drug was given specifically for sphincter spasticity. Four of them saw a satisfactory lowering of this spasticity at a dose of $25 \mathrm{mg} 3$ times a day. In the two other patients no notable effect was seen. 
Anal stretch was tried out by four patients with success in one only.

Local injection of anaesthetics (one or repeated injections) in the urethral sphincter had a favourable effect on dyssynergia in six out of 13 patients in whom it was given.

Sphincterotomy was performed in eight patients. In three a balanced bladder function was not obtained after surgery because of insufficient bladder contractility. In one patient moderate urinary incontinence occurred postoperatively because the bladder spasticity could not be managed successfully with medication.

The final outcome of the bladder reeducation is given in Table IV. Incontinence is a major problem in four patients with UMNL and dyssynergia who are on tapottage. They wear a condom catheter all the time.

Table IV Final outcome of the bladder re-education

\begin{tabular}{|c|c|c|c|c|c|c|c|c|c|}
\hline \multirow{2}{*}{$\begin{array}{l}\text { Type } \\
\text { lesion }\end{array}$} & \multirow{2}{*}{$\begin{array}{l}\text { Number of } \\
\text { patients }\end{array}$} & \multirow{2}{*}{$\begin{array}{l}\text { Sphincter } \\
\text { activity }\end{array}$} & \multicolumn{7}{|c|}{ Number of patients } \\
\hline & & & Total & $?$ & I.C. & Crédé & Tapott. & Spont. & Foley \\
\hline \multirow[t]{2}{*}{ UMNL } & 87 & dyssynergic & 75 & 3 & 16 & 10 & 36 & 6 & 4 \\
\hline & & synergic & 12 & 2 & 4 & 2 & 4 & 一 & - \\
\hline \multirow[t]{2}{*}{ LMNL } & 18 & spastic & 5 & - & 1 & 3 & - & 1 & - \\
\hline & & paralysed & 13 & - & 6 & 3 & - & 2 & 2 \\
\hline Total & 105 & & & 5 & 27 & 18 & 40 & 9 & 6 \\
\hline
\end{tabular}

I.C.: clean intermittent selfcatheterisation

Tapott.: suprapubic tapping

Spont.: spontaneous micturition

Foley: indwelling Foley catheter

?: data incomplete.

\section{Discussion}

Normal voiding is characterized by pre-voiding pelvic floor and urethral sphincter relaxation, a well sustained increase in intravesical pressure and maintenance of striated sphincter relaxation until voiding is complete. After spinal cord injury the co-ordinated function of bladder and sphincter can be altered. Pure detrusor striated sphincter dyssynergia is mostly found in patients with suprasacral spinal cord transsection after the period of spinal shock has passed. It can lead to severe functional obstruction often with dilatation of the upper urinary tract and impaired kidney function (Diokno et al., 1974).

We could demonstrate that, in the majority of patients with complete and incomplete suprasacral lesions, detrusor sphincter dyssynergia may and will occur during spontaneous bladder contraction, during bladder contraction provoked by suprapubic tapping and with crédé manoeuvre. This was mentioned also by Rossier and Fam (1979).

Interrupted tapping lowered the sphincter spasticity for a short time during which micturition could occur. In $28^{\circ}$ of the UMNL patients a balanced bladder function was obtained with this technique.

In patients with a non-contractile detrusor a spastic urethral sphincter was found in $28^{\circ}{ }_{0}$. Moreover it was shown that in one of these patients with apparently a lower motor neuron lesion, the crédé manoeuvre and straining were less indicated for bladder emptying as these augmented the sphincter spasticity and enhanced outflow obstruction. 
Such a condition should perhaps not be called a true dyssynergia as the term dyssynergia implicates a dyssynergic muscle action with respect to the action of another muscle (Wein, 1982).

Urodynamic investigations are mandatory for the evaluation of the function of the lower urinary tract in SCI (Wyndaele, 1984). Bladder pressure. sphincter electromyography, rectal pressure measurements during voiding, combined with fluoroscopy are ideal methods to investigate bladder sphincter interactions (Mayo and Kiviat, 1980).

It is preferable to investigate the urethral external sphincter itself with EMG as discordant activities between this muscle and the anal sphincter were noted in up to $39^{\circ}$ o of the patients (Koyanagi et al., 1982).

In the presence of detrusor-sphincter dyssynergia it is worthwhile to start treating all kinds of inflammation of the lower urinary tracts and decubiti located near the urogenital region as these may increase the symptoms of dyssynergia (Krane and Siroky, 1979).

In the pharmacological treatment for sphincter dyssynergia some drugs have been advocated. Baclofen gave favourable results in some of our patients at a much lower dose than was used by Leyson et al., 1980.

The effect of $\alpha$ blocking agents, advised by Buczynski 1984 in early treatment, and by Koyanagi et al. (1982) in the minor degrees of dyssynergia was not tried out by us. In the literature many important arguments are given against a sympathetic innervation of the external striated urethral sphincter (Rossier et al., 1983).

Other conservative means proved of value in some of our patients. This encouraged us to try out different forms of conservative treatment in all patients in whom they could be given and this not seldom was successful.

Sphincterotomy was used in eight patients. We think it is mandatory in all cases of severe dyssynergia which cannot be improved by any other means. In patients with less severe dyssynergia, and especially in those in whom it has tendency to diminish with time (cervical central cord syndrome) (Perkash, 1978) we continue pharmacological or other conservative treatment and/or clean intermittent self-catheterisation. As in all patients with spinal cord injury a life-long close follow-up is necessary whatever treatment is given.

Urological follow up till now (mean period of 2 years) showed no deterioration of the upper tract in any patient. None of the patients had to change his method of bladder emptying during the following period as no major complications occurred.

\section{References}

Blaivas JG, Barbalias GA 1984 Detrusor external sphincter dyssynergia in men with M.S.: an ominous urologic condition. Journal of Urology 131:91-94.

BUCZYNSKI A 1984 Urodynamic studies in evaluating detrusor sphincter dyssynergia and their effect on the treatment. Paraplegia 22:168-172.

DIOKNO A, KOFF S, BENDER L 1974 Periurethral striated muscle activity in neurogenic bladder dysfunction. Journal of Urology 112:743-749.

Koyanagi T, ARIKado K, TAKamatsu T, Tsuji T 1982 Experience with electromyography of the external urethral sphincter in Spinal Cord Injury patients. Journal of Urology 127:272-276.

Krane R, SiRoky M 1979 Clinical Neuro-Urology, Little Brown and Cie, Boston, p. 151-153.

LEYSON J, MARTIN B, SPORES A 1980 Baclofen in the treatment of detrusor sphincter dyssynergia in spinal cord injury patients. Journal of Urology 124:82-84. 
MADERSBACHER H 1976 The twelve o'clock sphincterotomy: technique, indications, results. Paraplegia 13:261-267.

MAYo M, Kiviat M 1980 Increased residual urine in patients with bladder neuropathy secondary to suprasacral spinal cord lesions. Journal of Urology 123:726-728.

MCGUIRE EJ 1984 Clinical evaluation and treatment of neurogenic vesical dysfunction. Williams and Wilkens, Baltimore, p. 69.

PERKASH I 1978 Detrusor-sphincter dyssynergia and dyssynergic responses: recognition and rationale for early modified transurethral sphincterotomy in complete spinal cord injury lesions. Journal of Urology 120:469:474.

Rossier A, FAM B 1979 From intermittent catheterisation to catheter freedom via urodynamics: a tribute to Sir Ludwig Guttman. Paraplegia 17:73-85.

Rossier A, Fam B, Lee I, Sarkarati M, Evans D 1983 The respective contribution of smooth and striated components in the urethral pressure profile of the spinal cord injured. A neuropharmacological and urodynamic study. Paraplegia 21:114-116.

SIROKY M, KRANE R 1982 Neurological aspects of detrusor-sphincter dyssynergia, with reference to the guarding reflex. Journal of Urology 127:953-957.

WEIN A 1982 Editorial comment. Journal of Urology 127:276.

WYNDAELE JJ 1984 A critical review of urodynamic investigations in spinal cord injury patients. Paraplegia 22:138-144. 